\title{
ERRATUM
}

\section{Erratum to: Well-Being and health-related interventions in small- and medium-sized enterprises: A meta-analytic review}

\author{
Christin Gerhardt ${ }^{1,2}$. Désirée Stocker ${ }^{1,3} \cdot$ Dominik Looser $^{3} \cdot$ Martin grosse Holtforth $^{3,4} \cdot$ Achim Elfering $^{1,2}$
}

Published online: 15 April 2020

○ Springer-Verlag GmbH Deutschland, ein Teil von Springer Nature 2020

\section{Erratum to:}

Z. Arb. Wiss. 2019

https://doi.org/10.1007/s41449-019-00154-1

The original version of this article unfortunately contains a mistake. The authors regret that the second affiliation of the co-author Martin grosse Holtforth was inadvertently omitted in the manuscript. The details given in this erratum are correct.

The online version of the original article can be found under https://doi.org/10.1007/s41449-019-00154-1.

Christin Gerhardt

christin.gerhardt@psy.unibe.ch

1 Abteilung für Arbeits- und Organisationspsychologie, Universität Bern, Fabrikstrasse 8, 3012 Bern, Switzerland

2 National Centre of Competence in Research, Affective Sciences, Universität Genf, Geneva, Switzerland

3 Abteilung für Klinische Psychologie, Universität Bern, Fabrikstrasse 8, 3012 Bern, Switzerland

4 Psychosomatic Competence Center, Inselspital, Haus C.L.Lory, U1 59, 3010 Bern, Switzerland 